\title{
Search for mutations in signaling pathways in head and neck squamous cell carcinoma
}

\author{
THAIS GULIM DE CARVALHO ${ }^{1}$, ANA CAROLINA DE CARVALHO ${ }^{1}$, DANIELLE CALHEIROS CAMPELO MAIA ${ }^{1}$, \\ JULIANA KAORI OGAWA ${ }^{1}$, ANDRE LOPES CARVALHO ${ }^{2}$ and ANDRE LUIZ VETTORE ${ }^{1}$ \\ ${ }^{1}$ Cancer Molecular Biology Laboratory, Department of Science Biology, Federal University of \\ São Paulo (UNIFESP), 04039-032, São Paulo, SP; ${ }^{2}$ Department of Head and Neck Surgery, \\ Barretos Cancer Hospital, 14784-400, Barretos, SP, Brazil
}

Received February 19, 2013; Accepted April 17, 2013

DOI: $10.3892 /$ or.2013.2455

\begin{abstract}
Mutations in JAK-STAT signaling pathway genes have been associated with the development of various hematological tumors, but have not been investigated in head and neck tumors, and the PIK3CA, BRAF and KRAS genes have been described in a few cases of head and neck squamous cell carcinoma (HNSCC). In the present study, we determined the mutation status in members of the MAPK, PI3K-AKT and JAK-STAT pathways in HNSCC. Mutations in the KRAS, $B R A F, P I K 3 C A, J A K 1$ and $J A K 2$ genes were evaluated in 94 HNSCCs by direct DNA sequencing analysis using cDNA synthesized from RNA extracted from patient tumor cells. All patients evaluated had wild-type $K R A S, B R A F$ and $P I K 3 C A$ genes. Furthermore, although some known polymorphisms have been found in $J A K 1$ genes (rs45598436, rs17127063, rs2230587, rs3737139, rs2230588 and rs12129819) and $J A K 2$ (rs10429491, rs2230723, rs2230724 and rs41316003), no mutation could be detected. Our data indicate that mutations in these kinase genes seem to be rare events in HNSCC.
\end{abstract}

\section{Introduction}

Head and neck cancer is among the 10 most common types of cancer, with more than 600,000 new cases diagnosed annually worldwide (1); the squamous cell carcinoma subtype is the most frequent, corresponding to $90 \%$ of all cases (2). This disease originates at distinct head and neck topologies including the oral cavity, the pharynx and the larynx. Due to the critical location in the upper aerodigestive tract, these types of cancer and their treatment significantly impair patient

Correspondence to: Professor Andre Luiz Vettore, Cancer Molecular Biology Laboratory, Department of Science Biology, Federal University of São Paulo (UNIFESP), Pedro de Toledo, 04039-032, São Paulo, SP, Brazil

E-mail: andre.vettore@gmail.com

Key words: head and neck cancer, squamous cell carcinoma, kinase, signaling pathway, mutation quality of life as they affect breathing, swallowing, speech and even appearance. In the past decades, a reduction in the mortality rates has been observed in carcinomas of different anatomical sites; however, this trend was not observed in the head and neck squamous cell carcinoma (HNSCC) (3). Despite different strategies used in the current treatment of HNSCC, a high percentage of these patients progresses with locoregional and distant recurrences (4). Therefore, identifying molecular aberrations in HNSCC may improve our understanding of head and neck carcinogenesis, allowing for the identification of new strategies for subdividing patients into biologically and clinically relevant subgroups, and highlighting novel therapeutic options.

Cancer is a progressive genetic disease characterized by the accumulation of genetic and epigenetic modifications. Among the most common genetic alterations are the mutations in coding and non-coding sequences (5) and the presence of mutations in the phosphorylation domain of protein kinases that have been linked to the development of various tumors. Therefore, protein kinase inhibitors have demonstrated a significant efficacy in the treatment of different types of cancer (6).

An important cellular signaling pathway is the RAF/MEK/ERK (MAPK) pathway, which plays a role in mediating cellular response to cell growth (7). Several studies have reported the presence of hotspot mutations in KRAS (codons 12 and 13) and BRAF (codons 469 and 600) which produce perpetually active proteins resulting in increased proliferation and survival signaling (8-13). There are few reports on the frequency of mutations in $K R A S$ and $B R A F$ genes in HNSCC cases (7,14-16).

$K R A S$ downstream effector pathways also include the PI3K-AKT molecular signaling cascade. The presence of mutations in PIK3CA hotspots (codons 542, 545 and 1047) was linked to increased cell survival by inhibiting apoptosis (17). Mutations in PIK3CA have been found in different types of human cancer, including lung, gastric, breast, ovarian, hepatocellular, pancreatic, esophageal and head and neck (18-22).

Aside from the MAPK pathway, the JAK-STAT signaling pathway also controls cell proliferation, differentiation and survival by transmitting signals from the plasma membrane to the cell nucleus (23). In cells, cytokine receptors are associated through its cytosolic domain to one of the four members of 
the JAK family of tyrosine kinases (JAK1, JAK2, JAK3 and TYK2). Conformational changes in the receptor enable JAKs to transphosphorylate and also phosphorylate the receptor itself, activating them. Both are capable of recruiting active substrates such as STAT proteins (signal transducer and activator of transcription proteins), which when phosphorylated, become active, translocate to the nucleus and regulate expression of different genes (23). In recent years, several studies have correlated the presence of mutations in proteins of the JAK-STAT pathway with hematopoietic disorders. High frequency of JAK2 V617F mutation is observed in myeloproliferative cases, whereas $J A K 1$ and $J A K 3$ sequence alterations have been found in cases of myeloid leukemia megakaryoblastic, acute lymphoblastic leukemia and lymphomas (24-26). In solid tumors, mutations in $J A K 1$ have been detected in lung and breast cancer and changes in the JAK3 gene were identified in breast and gastric carcinomas (27).

Therapies targeting inhibition of multiple points along the signal transduction pathways are potential new approaches in the treatment of cancer. In non-small cell lung cancer (NSCLC), the presence of activating mutations within the kinase domain of epidermal growth factor receptor (EGFR) is common (28). Therapeutic approaches based on drugs that inhibit the tyrosine kinase activity of this receptor (gefitinib and erlotinib) have improved survival rates for NSCLC patients (29).

Cetuximab, a chimeric monoclonal antibody against epidermal growth factor receptor (EGFR), is used in treatment of colorectal cancer (CRC). Recently, the presence of mutations in KRAS was described as a marker for the resistance to therapy with cetuximab in CRC (30). In other words, CRC patients carrying mutations in this oncogene cannot benefit from treatment with this drug, unlike patients whose tumors have wild-type KRAS.

Cetuximab is the only kinase-targeted therapy approved by the Food and Drug Administration (FDA) for the treatment of locally and regionally advanced HNSCC in combination with radiation. However, this agent generally presents only modest efficacy, and efforts to identify the subset of responsive patients who could benefit from this therapy have not been successful (31).

The aim of the present study was to examine the mutation status of $K R A S, B R A F, P I K 3 C A, J A K 1$ and JAK2 in primary head and neck cancer and to verify if the mutation status could identify specific molecular subgroups of HNSCC with clinical or therapeutic implications and if $K R A S$ mutations could be useful as a marker for the resistance to therapy with cetuximab in HNSCC.

\section{Materials and methods}

Patients. This retrospective study involved 94 tumor specimens obtained from patients diagnosed with HNSCC, who were treated at the Department of Head and Neck Surgery of Barretos Cancer Hospital (São Paulo, Brazil) between 2007 and 2010. These samples, available at the tumor bank of the Hospital, were collected during surgery for treatment of HNSCC. Tissue samples were snap-frozen in liquid nitrogen within $30 \mathrm{~min}$ after resection and stored at $-80^{\circ} \mathrm{C}$. Only patients diagnosed with primary HNSCC, not previously treated, that were over 18 years of age, treated surgically with curative intent and presenting with tumors at the oral cavity, the pharynx, or the larynx were included in the study. The HNSCC diagnoses were confirmed by a pathologist and all samples were examined microscopically for the presence of neoplastic tissue and the absence of contaminating normal mucosa.

The study protocol was reviewed and approved by the Ethics Committee of Barretos Cancer Hospital and was performed in accordance with the ethics guidelines of the 1975 Declaration of Helsinki.

RNA extraction and cDNA synthesis. Total RNA was extracted using TRIzol ${ }^{\circledR}$ reagent (Invitrogen, Carlsbad, CA, USA) following the manufacturer's recommendations. The concentration of the resulting RNA was measured using a spectrophotometer (NanoDrop 1000 Spectrophotometer, Thermo Fischer Scientific, Waltham, MA, USA) and the quality of the RNAs was checked by electrophoresis on $1 \%$ agarose gel stained with SYBR ${ }^{\circledR}$ Safe (Invitrogen).

Two micrograms of total RNA from each sample were used to synthesize cDNA molecules using SuperScript ${ }^{\circledR}$ III First-Strand Synthesis system (Invitrogen) according to the conditions provided by the manufacturer. The cDNA obtained was diluted 10x prior to use.

Sequencing analysis. PCR amplification of cDNA was performed and analyzed for mutations at hotspots of KRAS (codons 12 and 13), BRAF (codons 469 and 600) and PIK3CA (codons 542, 545 and 1047), as previously reported (32-34). To search for mutations in JAK1 and JAK2, primers were designed to generate seven fragments covering the entire coding region of each gene. All primers used in this study are presented in Table I.

Amplification reactions contained $1 \mu 1$ of cDNA as template in a $25 \mu \mathrm{l}$ reaction mixture consisting of $1 \mathrm{X}$ reaction buffer, $1 \mathrm{mmol} / \mathrm{l}$ deoxynucleotide triphosphate, $2 \mathrm{mmol} / \mathrm{l}$ magnesium, $200 \mathrm{nmol} / \mathrm{l}$ of each primer, and 1.2 unit Platinun Taq (Invitrogen). Following purification using QIAquick ${ }^{\circledR}$ Multiwell PCR Purification Kit (Qiagen, Hilden, Germany) and Gel Band Purification (GE Healthcare, Little Chalfont, Buckinghamshire, UK), the PCR products were subjected to sequencing (both directions) using BigDye ${ }^{\circledR}$ Terminator v3.1 sequencing kit (Applied Biosystems, Foster City, CA, USA), ethanol precipitation, and an automated sequencer (ABI PRISM 3130XL Genetic Analyzer; Applied Biosystems).

The sequences obtained were analyzed with the BioEdit Sequence Alignment Editor software (35) and the Phred/Phrap/Consed Package (36). The sequences were compared to a human reference sequence, available at UCSC Genome Bioinformatics (http://genome.ucsc.edu/). The annotation of the sequence variations identified was performed using the Ensembl database (http://www.ensembl.org/) and the NCBI database (http://www.ncbi.nlm.nih.gov/).

\section{Results}

Patient characteristics. Table II summarizes the clinical and histological characteristics of the patients enrolled in the study. Ninety four primary tumor samples were collected from untreated HNSCC patients (80 male and 14 female). Median age was 57.8 years (range, 32-82 years). Tobacco or alcohol 
Table I. Primers used for amplification of fragments from $B R A F, K R A S, P I K 3 C A, J A K 1$ and $J A K 2$ genes.

\begin{tabular}{|c|c|c|c|c|}
\hline Fragment & Sense & Sequence $5^{\prime}-3^{\prime}$ & Annealing temperature $\left({ }^{\circ} \mathrm{C}\right)$ & Size (bp) \\
\hline BRAF-11 ${ }^{\mathrm{b}}$ & $\begin{array}{l}\mathrm{F} \\
\mathrm{R}\end{array}$ & $\begin{array}{l}\text { GACGGGACTCGAGTGATGAT } \\
\text { CTGCTGAGGTGTAGGTGCTG }\end{array}$ & 62 & 155 \\
\hline BRAF-15 & $\begin{array}{l}\mathrm{F} \\
\mathrm{R}\end{array}$ & $\begin{array}{l}\text { GCACAGGGCATGGATTACTT } \\
\text { GATGACTTCTGGTGCCATCC }\end{array}$ & 62 & 195 \\
\hline KRAS $^{c}$ & $\begin{array}{l}\mathrm{F} \\
\mathrm{R}\end{array}$ & $\begin{array}{l}\text { GGCCTGCTGAAAATGACTGAA } \\
\text { CACAAAGAAAGCCCTCCCCA }\end{array}$ & 62 & 253 \\
\hline PI3K-9d & $\begin{array}{l}\mathrm{F}^{\mathrm{a}} \\
\mathrm{R}\end{array}$ & $\begin{array}{l}\text { AATTGGTCTGTATCCCGAG } \\
\text { CGGGGATAGTTACACAATAGT }\end{array}$ & 60 & 199 \\
\hline PI3K-20 & $\begin{array}{l}\mathrm{F}^{\mathrm{a}} \\
\mathrm{R}\end{array}$ & $\begin{array}{l}\text { TGGAATGCCAGAACTACAATC } \\
\text { ATGCTGTTTAATTGTGTGGAAG }\end{array}$ & 60 & 175 \\
\hline JAK1-1 & $\begin{array}{l}\mathrm{F} \\
\mathrm{R}\end{array}$ & $\begin{array}{l}\text { GCCCAGGCGCACACGGA } \\
\text { GACAGCCATCCCTAGCACTCGTTC }\end{array}$ & 62 & 680 \\
\hline JAK1-2 & $\begin{array}{l}\mathrm{F} \\
\mathrm{R}\end{array}$ & $\begin{array}{l}\text { TTTGGTGAAATGCCTGGCTCCTAT } \\
\text { CCACTCTTCCCGGATCTTGTTTTTC }\end{array}$ & 62 & 594 \\
\hline JAK1-3 & $\begin{array}{l}\mathrm{F} \\
\mathrm{R}\end{array}$ & $\begin{array}{l}\text { CTGGAAAATAAACACAAGAAGGATGAGGAG } \\
\text { CGGGGCTTGGGCTGGC }\end{array}$ & 62 & 610 \\
\hline JAK1-4 & $\begin{array}{l}\mathrm{F} \\
\mathrm{R}\end{array}$ & $\begin{array}{l}\text { AGCCACCTCAAGAAGCAGATCCTG } \\
\text { TGAGCTTGATGAATGGGCCACA }\end{array}$ & 62 & 642 \\
\hline JAK1-5 & $\begin{array}{l}\mathrm{F} \\
\mathrm{R}\end{array}$ & $\begin{array}{l}\text { GAAATGTGTGTACTAAAAACCTCCTCCTGG } \\
\text { TCCTTTTTCAGATCAGCTATGTGGTTACC }\end{array}$ & 62 & 636 \\
\hline JAK1-6 & $\begin{array}{l}\mathrm{F} \\
\mathrm{R}\end{array}$ & $\begin{array}{l}\text { GGGGACAATACAGGGGAGCAGG } \\
\text { GTGTAATACTCCTTATCGGTTTCAATTGCTTT }\end{array}$ & 62 & 408 \\
\hline JAK1-7 & $\begin{array}{l}\mathrm{F} \\
\mathrm{R}\end{array}$ & $\begin{array}{l}\text { TTCACCGGGACTTGGCAGCA } \\
\text { CATTTGTTGCAGGAGAAGGACTTGATAA }\end{array}$ & 62 & 525 \\
\hline JAK2-1 & $\begin{array}{l}\mathrm{F} \\
\mathrm{R}\end{array}$ & $\begin{array}{l}\text { AGAAGCAGGCAACAGGAACAAGATG } \\
\text { ACGTTCAGCACCTCGAGATATTCCAT }\end{array}$ & 62 & 529 \\
\hline JAK2-2 & $\begin{array}{l}\mathrm{F} \\
\mathrm{R}\end{array}$ & $\begin{array}{l}\text { TGAGTCAACCAGGCATAATGTACTCTACAG } \\
\text { CCTCTTGACCACTGAATTCCACCG }\end{array}$ & 62 & 588 \\
\hline JAK2-3 & $\begin{array}{l}\mathrm{F} \\
\mathrm{R}\end{array}$ & $\begin{array}{l}\text { GGAAACTCTGCAGTCTGCCTTCTACAC } \\
\text { AGTTCTTCTTTGTCCCACTGAGGTTGTAC }\end{array}$ & 62 & 638 \\
\hline JAK2-4 & $\begin{array}{l}\mathrm{F} \\
\mathrm{R}\end{array}$ & $\begin{array}{l}\text { TTTTTGACTTTTGCTGTCGAGCGA } \\
\text { TTCTTCTAGAAAATGCATGGCCCA }\end{array}$ & 62 & 693 \\
\hline JAK2-5 & $\begin{array}{l}\mathrm{F} \\
\mathrm{R}\end{array}$ & $\begin{array}{l}\text { TGGAGTATGTGTCTGTGGAGACGAGAA } \\
\text { AACTGTGTAGGATCCCGGTCTTCAAA }\end{array}$ & 62 & 693 \\
\hline JAK2-6 & $\begin{array}{l}\mathrm{F} \\
\mathrm{R}\end{array}$ & $\begin{array}{l}\text { GCCTTCTTTCAGAGCCATCATACGA } \\
\text { CTCTCTGTCAGTGATTCTGGAGCATACC }\end{array}$ & 62 & 703 \\
\hline JAK2-7 & $\begin{array}{l}\mathrm{F} \\
\mathrm{R}\end{array}$ & $\begin{array}{l}\text { CGAGAAATATATTGGTGGAGAACGAGAAC } \\
\text { AATGTCTTTTACTGGTGGCCTCATGAA }\end{array}$ & 62 & 659 \\
\hline
\end{tabular}

${ }^{\mathrm{a}}$ Minor modifications in the primer sequences with respect to the sequences previously described. Described references: ${ }^{\mathrm{b}}(32),{ }^{\mathrm{c}}(33),{ }^{\mathrm{d}}(34)$.

consumption (current or former) was reported by 91.2 and $74.7 \%$ patients, respectively. Primary tumor sites included: oral cavity $(70.2 \%)$, larynx $(14.9 \%)$, oropharynx $(12.8 \%)$ and hypopharynx $(2.1 \%)$. Regarding tumor stage, the majority was T3/T4 (81.7\%). Forty two patients presented positive lymph nodes, among those $15(19.0 \%)$ presented extracapsular spread. Perineural invasion was detected in 24 cases $(27.0 \%)$ among 89 patients with data available, while lymphovascular invasion was observed in 15 cases $(17.4 \%)$ among 86 patients with data available. 
Table II. Demographic and clinical characteristics of the HNSCC patients included in this study $(n=94)$.

\begin{tabular}{|c|c|c|}
\hline Parameter & $\mathrm{n}$ & $\%$ \\
\hline \multicolumn{3}{|l|}{ Age (years) } \\
\hline$<55$ & 33 & 35.1 \\
\hline$\geq 55$ & 61 & 64.9 \\
\hline Mean & 57.8 & \\
\hline Range & $32-82$ & \\
\hline \multicolumn{3}{|l|}{ Gender } \\
\hline Male & 80 & 85.1 \\
\hline Female & 14 & 14.9 \\
\hline \multicolumn{3}{|c|}{ Tobacco consumption } \\
\hline Yes & 83 & 91.2 \\
\hline No & 8 & 8.8 \\
\hline \multicolumn{3}{|c|}{ Alcohol consumption } \\
\hline Yes & 65 & 74.7 \\
\hline No & 22 & 25.3 \\
\hline \multicolumn{3}{|l|}{ Tumor site } \\
\hline Oral cavity & 66 & 70.2 \\
\hline Larynx & 14 & 14.9 \\
\hline Oropharynx & 12 & 12.8 \\
\hline Hypopharynx & 2 & 2.1 \\
\hline \multicolumn{3}{|l|}{ T stage ${ }^{\mathrm{a}}$} \\
\hline $\mathrm{T} 1 / \mathrm{T} 2$ & 17 & 18.3 \\
\hline $\mathrm{T} 3 / \mathrm{T} 4$ & 76 & 81.7 \\
\hline \multicolumn{3}{|l|}{$\mathrm{N}$ stage } \\
\hline No & 41 & 49.4 \\
\hline $\mathrm{N}+$ & 42 & 50.6 \\
\hline \multicolumn{3}{|c|}{ Extracapsular spread } \\
\hline Yes & 15 & 19.0 \\
\hline No & 64 & 81.0 \\
\hline \multicolumn{3}{|c|}{ Perineural invasion } \\
\hline Yes & 24 & 27.0 \\
\hline No & 65 & 73.0 \\
\hline \multicolumn{3}{|c|}{ Lymphovascular invasion } \\
\hline Yes & 15 & 17.4 \\
\hline No & 71 & 82.6 \\
\hline
\end{tabular}

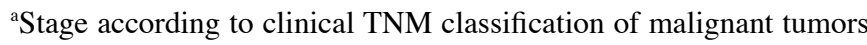
(TNM Classification of Malignant Tumours, 6th edition).

Mutation analysis. The presence of sequence variations in the hotspots previously described in the coding regions of KRAS (codons 12 and 13), BRAF (codons 469 and 600) and PIK3CA (codons 542, 545 and 1047) was examined in cDNA molecules from 94 HNSCC specimens. The assembly of the consensus sequences, as well as the evaluation of base qualities, were conducted with Phred/Phrap/Consed Package (36). No somatic mutations were detected in any of these genes in all cases examined. Representative cases are shown in Fig. 1.
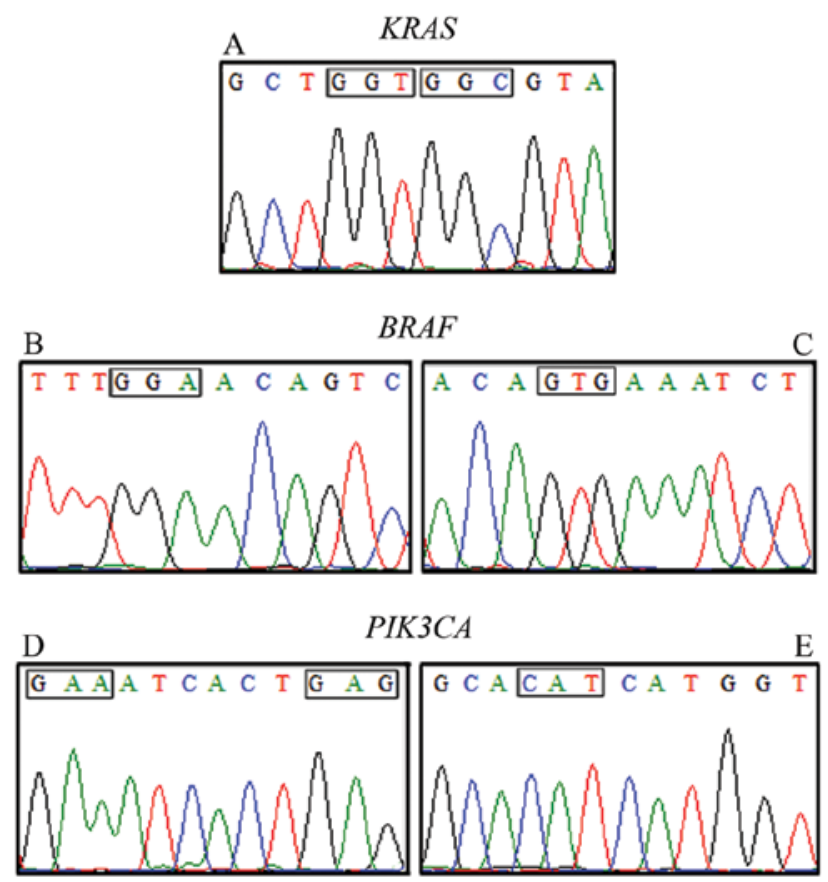

Figure 1. DNA sequencing performed on tumor samples of 94 patients with HNSCC. Representative cases of wild-type $K R A S$ codons 12 and 13 (A), BRAF codons 469 (B) and 600 (C), and PIK3CA codons 542, 545 (D) and 1047 (E).

Mutations in $J A K 1$ and $J A K 2$ genes have been reported in different types of cancer, mainly in hematological malignances; however, no hotspots were identified in the sequence of these genes. Therefore, primers were designed to generate overlapping fragments covering the entire coding region of $J A K 1$ (seven fragments, size 408 to $680 \mathrm{bp}$ ) and JAK2 (seven fragments, size 529 to $703 \mathrm{bp}$ ). We searched for sequence variations in $20 \mathrm{HNSCC}$ samples, but were not able to detect any mutations within the $J A K 1$ and $J A K 2$ coding sequences.

The analysis of the complete sequences from $J A K 1$ and $J A K 2$ genes allowed the identification of some sequence variations reported as polymorphisms in the Ensembl database. JAK1 presented 6 different polymorphisms at positions $579 \mathrm{~T}>\mathrm{C}$ (codon 193), $1977 \mathrm{C}>\mathrm{T}$ (codon 659), $2049 \mathrm{C}>\mathrm{T}$ (codon 683), $2097 \mathrm{C}>\mathrm{G}$ (codon 699), $2199 \mathrm{~A}>\mathrm{G}$ (codon 733) and $3096 \mathrm{G}>\mathrm{A}$ (codon 1032). Of note, none of these alterations resulted in amino acid changes (Table III). For JAK2, we found four different polymorphisms at positions $489 \mathrm{C}>\mathrm{T}$ (codon 163), $1177 \mathrm{C}>\mathrm{G}$ (codon 393), $2490 \mathrm{G}>\mathrm{A}$ (codon 830) and $3188 \mathrm{G}>\mathrm{A}$ (codon 1063) (Table IV). The alteration of the $\mathrm{C}$ nucleotide by a $\mathrm{G}$ at position 1177 promotes a substitution of a Leucine residue by a Valine (codon 393), whereas the replacement of $\mathrm{G}$ at position 3188 by an $\mathrm{A}$ induces the change of an Arginine by a Histidine (codon 1063) (Table IV).

\section{Discussion}

The management of HNSCC patients has improved in recent years with developments in surgical techniques, the introduction of altered fractionation radiation, new chemotherapeutic agents, and combined use of chemoradiotherapy; however, long-term survival rates have improved only marginally, and the 5-year overall survival rate remains approximately $50 \%$ (3). 
Table III. Single nucleotide polymorphisms (SNPs) of the JAK1 gene found in 20 HNSCC samples analyzed.

\begin{tabular}{lccccc}
\hline SNP & Codon & Exon & Amino acid & No. of cases & Frequency observed (\%) \\
\hline rs 45598436 & 193 GCT>GCC & 6 & Ala $>$ Ala & 4 & 20 \\
rs 17127063 & 659 CGC>CGT & 14 & Arg $>$ Arg & 1 & 5 \\
rs 2230587 & 683 AGC $>$ AGT & 15 & Ser $>$ Ser & 6 & 30 \\
rs 3737139 & 699 GCC $>$ GCG & 15 & Ala $>$ Ala & 1 & 5 \\
rs 2230588 & 733 CCA $>$ CCG & 16 & Pro $>$ Pro & 5 & 25 \\
rs 12129819 & 1032 AAG $>$ AAA & 22 & Lys $>$ Lys & 4 & 20 \\
\hline
\end{tabular}

Table IV. Single nucleotide polymorphisms (SNPs) of the JAK2 gene found in 20 HNSCC samples analyzed.

\begin{tabular}{lccccc}
\hline SNP & Codon & Exon & Amino acid & No. of cases & Frequency observed (\%) \\
\hline rs 10429491 & 163 CAC>CAT & 7 & His $>$ His & 13 & 65 \\
rs 2230723 & 393 CTT>GTT & 9 & Leu>Val & 1 & 5 \\
rs 2230724 & 830 CTG $>$ CTA & 20 & Leu>Leu & 17 & 85 \\
rs 41316003 & 1063 CGT>CAT & 25 & Arg $>$ His & 2 & 10 \\
\hline
\end{tabular}

To date, two promising strategies tested for the treatment of HNSCC are blocking growth factors signaling pathways and interfering in pathways related to angiogenesis. EGFR has been studied extensively as a therapeutic target due to its high expression in different tumors and its influence in the regulation of proliferation, apoptosis, metastasis, angiogenesis, and cell differentiation. The extracellular portion of EGFR can be inhibited by monoclonal antibodies and intracellular part by tyrosine kinase inhibitors. The monoclonal antibody cetuximab, an EGFR extracellular inhibitor, has been used in the treatment of colorectal tumors (37). Therapies targeting epidermal growth factor receptor (EGFR/HER-1/ERBB1) pathways have also been used in HNSCC, but only a minority of patients have benefited from these treatments, since smallmolecule tyrosine kinase inhibitors (gefitinib and erlotinib) and monoclonal antibodies against EGFR (cetuximab) have shown limited efficacy (38-40).

It is well known that cetuximab prolongs overall survival of locally advanced HNSCC patients when delivered in combination with radiation (41). This drug has also shown activity in the first-line treatment of recurrent and/or metastatic HNSCC in combination with cisplatin or cisplatin/fluorouracil $(42,43)$. However, the response rates of cetuximab as a single agent are approximately $13 \%$ (40). Thus, the identification of clinically effective markers for selection of HNSCC patients responsive to cetuximab therapy is of paramount importance.

In colorectal cancer, there is a well-established association between the presence of mutations in KRAS and the response to cetuximab treatment (30). Considering all types of human cancer, KRAS mutations are the most common type of Ras mutation, with HRAS being the least common; however, in head and neck cancer, Ras mutations appear to be exclusively $H R A S$ mutations (44). To date, few studies have attempted to assess the KRAS mutation status in HNSCC and their results are contradictory. In a recent study, Smilek et al (14) examined the KRAS mutation status of 27 HNSCC patients and found alterations in $14.8 \%$ (4/27) of the cases. Weber et al (7) found KRAS mutations in 6\% (3/89) of HNSCC samples examined, while Van Damme et al (15) evaluated 22 HNSCC specimens and identified a mutation in one case (4.5\%). On the other hand, no KRAS mutation was detected among 183 HNSCC samples investigated from a Japanese cohort (45). Mutations in the KRAS gene were also infrequent in oral squamous cell carcinomas (OSCCs) $(16,46,47)$. In the present study, wildtype KRAS was detected in all 94 HNSCC samples evaluated. In light of these findings and in contrast to colorectal cancer, our results together with others indicate that KRAS mutations may not be considered a predictor of sensitivity to cetuximab in HNSCC.

As well as the RAS family, another member of the MAPK pathway is $B R A F$. Somatic point mutations of $B R A F$, such as those that occur at hotspot V600E of its kinase domain, can result in elevated BRAF kinase function (48). Mutations in this gene have been associated with various types of cancer, including non-Hodgkin lymphoma, colorectal cancer, thyroid cancer and lung carcinoma $(10,11,49,50)$. A German study found BRAF mutated in 3\% (3/89) of HNSCC cases evaluated (7), while a study evaluating American HNSCC patients reported $B R A F$ mutations in $2.4 \%(1 / 42)$ of the cases (16). In the present study, none of the 94 samples analyzed presented alterations in $B R A F$ sequence.

Mutations in PIK3CA, the catalytic subunit of PI3-kinase, are reported to have higher oncogenic potential. Recent exome sequencing analyses revealed $P I K 3 C A$ activating mutations in 6-8\% of HNSCC $(51,52)$. Two independent studies, evaluating 38 HNSCC samples and 37 OSCC specimens, identified PIK3CA mutations in approximately $11 \%$ of the cases $(47,53)$. Kozaki et al (54) detected mutations in PIK3CA in 7.4\% (8/108) of OSCC, whereas Fenic et al (55) and Bruckman et al (16) found a lower frequency of mutations in HNSCC (2.9 and 3\%, 
respectively). A study analyzing South-Asian HNSCC patients found PIK3CA mutations in $10.5 \%$ (2/19) of the Indian cases, while only wild-type $P I K 3 C A$ was detected in Vietnamese tumors (0/18) (56). We did not identify any PIK3CA mutations in all 94 HNSCC patients evaluated. It should be noted that we are unable to discuss the presence of mutations in other gene regions not within hotspots previously described in $K R A S$, $B R A F$ and PIK3CA.

The MAPK and PI3K-AKT signaling pathways are involved in HNSCC tumorigenesis, but the oncogenic activation of these pathways may include additional mechanisms other than point mutations, such as chromosomal amplification or gene overexpression. Consistent with this, PIK3CA was found frequently amplified in OSCC (57-59) and Hoa et al (60) detected increased expression of KRAS in HNSCC cell lines.

The JAK-STAT signaling pathway is essential for the physiology of healthy individuals as it mediates cytokine responses in hematopoietic cells. This pathway is also responsible for regulating the hormone receptor signaling, including various growth hormones and prolactin receptors. In recent years, several mutations in $J A K$ genes associated with constitutive activation were identified and it is possible that mutations in this pathway component are present in various types of cancer (23). It is important to define the role of this pathway in solid tumors, as new therapeutic agents that have JAK as target are being developed and some JAK kinase inhibitors are already being tested in clinical trials (61).

Mutations in $J A K$ genes are commonly found in hematological tumors (62-64); however, few mutations have been described in solid tumors, such as breast, lung and gastric tumors (27). To the best of our knowledge, our study is the first to search for $J A K$ mutations in HNSCC. We analyzed the complete cDNA sequence of $J A K 1$ and $J A K 2$ genes in 20 HNSCC samples and, although some known polymorphisms have been evidenced, no mutation could be detected.

In conclusion, the present study investigated the presence of mutations in JAK1 and JAK2 genes in HNSCC patients examined and also evaluated the presence of sequence alterations in PIK3CA, BRAF and KRAS genes. Overall, no mutation in these genes could be detected in the HNSCC specimens examined. Also, KRAS mutation suggests that alterations in this gene do not seem to be useful as a cetuximab predictor of sensitivity in HNSCC.

\section{Acknowledgements}

The present study was supported by Fundação de Amparo à Pesquisa do Estado de São Paulo-FAPESP grant (2008/58460-9). T.G.C was the recipient of a scholarship from Coordenação de Aperfeiçoamento de Pessoal de Nível Superior-CAPES. A.C.C. was the recipient of a scholarship from Fundação de Amparo à Pesquisa do Estado de São Paulo-FAPESP. J.K.O was the recipient of scholarships from the National Counsel of Technological and Scientific Development-CNPq. A.L.C. has a National Counsel of Technological and Scientific Development-CNPq scholarship (313181/2009-8). A.L.V. has a National Counsel of Technological and Scientific Development-CNPq scholarship (302360/2008-5).

\section{References}

1. Ferlay J, Shin HR, Bray F, Forman D, Mathers C and Parkin DM: Estimates of worldwide burden of cancer in 2008: GLOBOCAN 2008. Int J Cancer 127: 2893-2917, 2010.

2. Wong DT, Todd R, Tsuji T and Donoff RB: Molecular biology of human oral cancer. Crit Rev Oral Biol Med 7: 319-328, 1996.

3. Carvalho AL, Nishimoto IN, Califano JA and Kowalski LP: Trends in incidence and prognosis for head and neck cancer in the United States: a site-specific analysis of the SEER database. Int J Cancer 114: 806-816, 2005.

4. Hinerman RW, Mendenhall WM, Morris CG, Amdur RJ, Werning JW and Villaret DB: Postoperative irradiation for squamous cell carcinoma of the oral cavity: 35 -year experience. Head Neck 26: 984-994, 2004.

5. Aaltonen LA, Peltomaki P, Leach FS, et al: Clues to the pathogenesis of familial colorectal cancer. Science 260: 812-816, 1993.

6. Greenman C, Stephens P, Smith R, et al: Patterns of somatic mutation in human cancer genomes. Nature 446: 153-158, 2007.

7. Weber A, Langhanki L, Sommerer F, Markwarth A, Wittekind C and Tannapfel A: Mutations of the BRAF gene in squamous cell carcinoma of the head and neck. Oncogene 22: 4757-4759, 2003.

8. Matthaios D, Zarogoulidis P, Balgouranidou I, Chatzaki E and Kakolyris S: Molecular pathogenesis of pancreatic cancer and clinical perspectives. Oncology 81: 259-272, 2011.

9. Santarpia L, El-Naggar AK, Cote GJ, Myers JN and Sherman SI Phosphatidylinositol 3-kinase/akt and ras/raf-mitogen-activated protein kinase pathway mutations in anaplastic thyroid cancer. J Clin Endocrinol Metab 93: 278-284, 2008.

10. Rowe LR, Bentz BG and Bentz JS: Detection of BRAF V600E activating mutation in papillary thyroid carcinoma using PCR with allele-specific fluorescent probe melting curve analysis. J Clin Pathol 60: 1211-1215, 2007.

11. Tie J, Gibbs P, Lipton L, et al: Optimizing targeted therapeutic development: analysis of a colorectal cancer patient population with the BRAF(V600E) mutation. Int J Cancer 128: 2075-2084, 2011.

12. Kullmann F, Hartmann A, Stohr R, et al: KRAS mutation in metastatic pancreatic ductal adenocarcinoma: results of a multicenter phase II study evaluating efficacy of cetuximab plus gemcitabine/oxaliplatin (GEMOXCET) in first-line therapy. Oncology 81: 3-8, 2011.

13. Rako I, Jakic-Razumovic J, Caban D, et al: The role of KRAS gene mutation testing in colorectal cancer - a predictive biomarker of response to EGFR inhibitors therapy. Lijec Vjesn 133: 403-407, 2011 (In Croatian).

14. Smilek P, Neuwirthova J, Jarkovsky J, et al: Epidermal growth factor receptor (EGFR) expression and mutations in the EGFR signaling pathway in correlation with anti-EGFR therapy in head and neck squamous cell carcinomas. Neoplasma 59: 508-515, 2012.

15. Van Damme N, Deron P, Van Roy N, et al: Epidermal growth factor receptor and K-RAS status in two cohorts of squamous cell carcinomas. BMC Cancer 10: 189, 2010.

16. Bruckman KC, Schonleben F, Qiu W, Woo VL and Su GH: Mutational analyses of the BRAF, KRAS, and PIK3CA genes in oral squamous cell carcinoma. Oral Surg Oral Med Oral Pathol Oral Radiol Endod 110: 632-637, 2010.

17. Rameh LE and Cantley LC: The role of phosphoinositide 3-kinase lipid products in cell function. J Biol Chem 274: 8347-8350, 1999.

18. Lee JW, Soung YH, Kim SY, et al: PIK3CA gene is frequently mutated in breast carcinomas and hepatocellular carcinomas. Oncogene 24: 1477-1480, 2005.

19. Levine DA, Bogomolniy F, Yee CJ, et al: Frequent mutation of the PIK3CA gene in ovarian and breast cancers. Clin Cancer Res 11: 2875-2878, 2005.

20. Phillips WA, Russell SE, Ciavarella ML, et al: Mutation analysis of PIK3CA and PIK3CB in esophageal cancer and Barrett's esophagus. Int J Cancer 118: 2644-2646, 2006.

21. Schonleben F, Qiu W, Ciau NT, et al: PIK3CA mutations in intraductal papillary mucinous neoplasm/carcinoma of the pancreas. Clin Cancer Res 12: 3851-3855, 2006.

22. Wu G, Mambo E, Guo Z, et al: Uncommon mutation, but common amplifications, of the PIK3CA gene in thyroid tumors. J Clin Endocrinol Metab 90: 4688-4693, 2005.

23. Constantinescu SN, Girardot M and Pecquet C: Mining for JAK-STAT mutations in cancer. Trends Biochem Sci 33: 122-131, 2008. 
24. Flex E, Petrangeli V, Stella L, et al: Somatically acquired JAK1 mutations in adult acute lymphoblastic leukemia. J Exp Med 205: 751-758, 2008.

25. Walters DK, Mercher T, Gu TL, et al: Activating alleles of JAK3 in acute megakaryoblastic leukemia. Cancer Cell 10 $65-75,2006$

26. Melzner I, Bucur AJ, Bruderlein S, et al: Biallelic mutation of SOCS-1 impairs JAK2 degradation and sustains phospho-JAK2 action in the MedB-1 mediastinal lymphoma line. Blood 105 2535-2542, 2005.

27. Jeong EG, Kim MS, Nam HK, et al: Somatic mutations of JAK1 and JAK 3 in acute leukemias and solid cancers. Clin Cancer Res 14: 3716-3721, 2008.

28. Tokumo M, Toyooka S, Kiura K, et al: The relationship between epidermal growth factor receptor mutations and clinicopathologic features in non-small cell lung cancers. Clin Cancer Res 11: $1167-1173,2005$

29. Rosell R, Moran T, Carcereny E, et al: Non-small-cell lung cancer harbouring mutations in the EGFR kinase domain. Clin Transl Oncol 12: 75-80, 2010.

30. Siddiqui AD and Piperdi B: KRAS mutation in colon cancer: a marker of resistance to EGFR-I therapy. Ann Surg Oncol 17: $1168-1176,2010$

31. Licitra L, Mesia R, Rivera F, et al: Evaluation of EGFR gene copy number as a predictive biomarker for the efficacy of cetuximab in combination with chemotherapy in the first-line treatment of recurrent and/or metastatic squamous cell carcinoma of the head and neck: EXTREME study. Ann Oncol 22: 1078-1087, 2011.

32. Nikiforova MN, Kimura ET, Gandhi M, et al: BRAF mutations in thyroid tumors are restricted to papillary carcinomas and anaplastic or poorly differentiated carcinomas arising from papillary carcinomas. J Clin Endocrinol Metab 88: 5399-5404, 2003.

33. Mathur A, Moses W, Rahbari R, et al: Higher rate of BRAF mutation in papillary thyroid cancer over time: a single-institution study. Cancer 117: 4390-4395, 2011.

34. Mori R, Ishiguro H, Kimura M, et al: PIK3CA mutation status in Japanese esophageal squamous cell carcinoma. J Surg Res 145: 320-326, 2008

35. Hall TA: BioEdit: a user-friendly biological sequence alignment editor and analysis program for Windows 95/98/NT. Nucleic Acids Symposium Series 41: 95-98, 1999.

36. Ewing B, Hillier L, Wendl M and Green P: Base-calling of automated sequencer traces using phred. I. Accuracy assessment. Genome Res 8: 175-185, 1998.

37. Bianchini C, Ciorba A, Pelucchi S, Piva R and Pastore A Targeted therapy in head and neck cancer. Tumori 97: 137-141, 2011.

38. Cohen EE, Kane MA, List MA, et al: Phase II trial of gefitinib $250 \mathrm{mg}$ daily in patients with recurrent and/or metastatic squamous cell carcinoma of the head and neck. Clin Cancer Res 11: 8418-8424, 2005.

39. Soulieres D, Senzer NN, Vokes EE, Hidalgo M, Agarwala SS and Siu LL: Multicenter phase II study of erlotinib, an oral epidermal growth factor receptor tyrosine kinase inhibitor, in patients with recurrent or metastatic squamous cell cancer of the head and neck. J Clin Oncol 22: 77-85, 2004.

40. Vermorken JB, Trigo J, Hitt R, et al: Open-label, uncontrolled, multicenter phase II study to evaluate the efficacy and toxicity of cetuximab as a single agent in patients with recurrent and/or metastatic squamous cell carcinoma of the head and neck who failed to respond to platinum-based therapy. J Clin Oncol 25: 2171-2177, 2007.

41. Bonner JA, Harari PM, Giralt J, et al: Radiotherapy plus cetuximab for squamous-cell carcinoma of the head and neck. N Engl J Med 354: 567-578, 2006.

42. Burtness B, Goldwasser MA, Flood W, Mattar B and Forastiere AA: Phase III randomized trial of cisplatin plus placebo compared with cisplatin plus cetuximab in metastatic/recurrent head and neck cancer: an Eastern Cooperative Oncology Group study. J Clin Oncol 23: 8646-8654, 2005.

43. Bourhis J, Rivera F, Mesia R, et al: Phase I/II study of cetuximab in combination with cisplatin or carboplatin and fluorouracil in patients with recurrent or metastatic squamous cell carcinoma of the head and neck. J Clin Oncol 24: 2866-2872, 2006.
44. Loyo M, Li RJ, Bettegowda C, et al: Lessons learned from nextgeneration sequencing in head and neck cancer. Head Neck 35 : 454-463, 2012.

45. Fujii S, Uryu H, Akashi K, et al: Clinical significance of KRAS gene mutation and epidermal growth factor receptor expression in Japanese patients with squamous cell carcinoma of the larynx, oropharynx and hypopharynx. Int J Clin Oncol: Mar 24, 2012 (Epub ahead of print)

46. Chang SE, Bhatia P, Johnson NW, et al: Ras mutations in United Kingdom examples of oral malignancies are infrequent. Int J Cancer 48: 409-412, 1991.

47. Cohen Y, Goldenberg-Cohen N, Shalmon B, et al: Mutational analysis of PTEN/PIK3CA/AKT pathway in oral squamous cell carcinoma. Oral Oncol 47: 946-950, 2011.

48. Mercer KE and Pritchard CA: Raf proteins and cancer: B-Raf is identified as a mutational target. Biochim Biophys Acta 1653: $25-40,2003$.

49. Lee JW, Yoo NJ, Soung YH, et al: BRAF mutations in nonHodgkin's lymphoma. Br J Cancer 89: 1958-1960, 2003.

50. Kobayashi M, Sonobe M, Takahashi T, et al: Clinical significance of BRAF gene mutations in patients with non-small cell lung cancer. Anticancer Res 31: 4619-4623, 2011.

51. Agrawal N, Frederick MJ, Pickering CR, et al: Exome sequencing of head and neck squamous cell carcinoma reveals inactivating mutations in NOTCH1. Science 333: 1154-1157, 2011.

52. Stransky N, Egloff AM, Tward AD, et al: The mutational landscape of head and neck squamous cell carcinoma. Science 333: 1157-1160, 2011.

53. Qiu W, Schonleben F, Li X, et al: PIK3CA mutations in head and neck squamous cell carcinoma. Clin Cancer Res 12: 1441-1446, 2006.

54. Kozaki K, Imoto I, Pimkhaokham A, et al: PIK3CA mutation is an oncogenic aberration at advanced stages of oral squamous cell carcinoma. Cancer Sci 97: 1351-1358, 2006.

55. Fenic I, Steger K, Gruber C, Arens C and Woenckhaus J: Analysis of PIK3CA and Akt/protein kinase B in head and neck squamous cell carcinoma. Oncol Rep 18: 253-259, 2007.

56. Murugan AK, Hong NT, Fukui Y, Munirajan AK and Tsuchida N: Oncogenic mutations of the PIK3CA gene in head and neck squamous cell carcinomas. Int J Oncol 32: 101-111, 2008

57. Estilo CL, P OC, Ngai I, et al: The role of novel oncogenes squamous cell carcinoma-related oncogene and phosphatidylinositol 3-kinase p110alpha in squamous cell carcinoma of the oral tongue. Clin Cancer Res 9: 2300-2306, 2003.

58. Freier K, Schwaenen C, Sticht C, et al: Recurrent FGFR1 amplification and high FGFR1 protein expression in oral squamous cell carcinoma (OSCC). Oral Oncol 43: 60-66, 2007.

59. Liu CJ, Lin SC, Chen YJ, Chang KM and Chang KW: Arraycomparative genomic hybridization to detect genomewide changes in microdissected primary and metastatic oral squamous cell carcinomas. Mol Carcinog 45: 721-731, 2006.

60. Hoa M, Davis SL, Ames SJ and Spanjaard RA: Amplification of wild-type K-ras promotes growth of head and neck squamous cell carcinoma. Cancer Res 62: 7154-7156, 2002.

61. Lai SY and Johnson FM: Defining the role of the JAK-STAT pathway in head and neck and thoracic malignancies: implications for future therapeutic approaches. Drug Resist Updat 13: $67-78,2010$

62. Baxter EJ, Scott LM, Campbell PJ, et al: Acquired mutation of the tyrosine kinase JAK2 in human myeloproliferative disorders. Lancet 365: 1054-1061, 2005.

63. Levine RL, Wadleigh M, Cools J, et al: Activating mutation in the tyrosine kinase JAK2 in polycythemia vera, essential thrombocythemia, and myeloid metaplasia with myelofibrosis. Cancer Cell 7: 387-397, 2005.

64. Colaizzo D, Amitrano L, Tiscia GL, Grandone E, Guardascione MA and Margaglione M: A new JAK2 gene mutation in patients with polycythemia vera and splanchnic vein thrombosis. Blood 110: 2768-2769, 2007. 